\title{
Image Promotion of Lebu Sishu Tourist Supermarket on New Media
}

\author{
Li Ren \\ Tianjin Polytechnic University \\ Tianjin, China
}

\author{
Baitong Li \\ Tianjin Polytechnic University \\ Tianjin, China
}

\begin{abstract}
In the information era, new media has a great impact on traditional media at a high speed. Now, new media has changed the way people use the media and makes people's life more convenient. The development of technology determines in what direction the media industry is developing. New media will become a mainstream in the future media industry. In the new era, the tourism industry as a tertiary industry has developed rapidly with the new media. The new media mainly including smartphones and the Internet offers a wider platform for promotion and marketing of tourism products. This paper mainly explains how to utilize new media as a medium to publicize Lebu Sishu tourist supermarket and image design and promotion of new media. Above all, it lets the audience know about image, function, and other aspects of Lebu Sishu tourist supermarket in the way of publicizing through the combination of new media and traditional media.
\end{abstract}

Keywords-new media; design; Lebu Sishu tourist supermarket; publicity

\section{INTRODUCTION}

Influenced by the new media and tourism industry, tourist supermarket forms and has been developing rapidly in the circumstance that people's living standard is improving.

This paper mainly explains how to utilize new media as a medium to publicize Lebu Sishu tourist supermarket and image design and promotion of new media. As the super online platform which provides tourism products and services, tourist supermarket has gradually become an indispensable product when people are traveling.

Tourist supermarket has become the most prominent part of the whole supermarket field in Europe and the United States. Compared with foreign tourist supermarket, those in China started late, which is still at an early stage. There is a big gap between tourist supermarket in developed countries and those in China, so I want the audience know about image, function, and other aspects of Lebu Sishu tourist supermarket in the way of visually publicizing through the combination of new media and traditional media such as video, web and mobile phone.

\section{PRODUCT OVERVIEW}

\section{A. Introduction to Tourist Supermarkets}

Tourist supermarket just as its name stands for a network market including tourism products and services, such as Tuniu and Ctrip, etc. It provides tourists with comprehensive local travel guides and tourist routes in the world. It's also a platform involved with a variety of tourism products and travel booking service about food, accommodation, travel and so on.

The concept of tourist supermarket is people-oriented, which meets the needs of all kinds of tourists through various kinds of tourism programs and the introduction of all-round and multi-level tourism products. Audiences of all ages and of different genders can be satisfied on the service platform; it strives to make family with three generations or five generations have fun together. It makes the trip more convenient, colorful, scheduled and more interesting.

\section{B. Overview of Tourism in Sichuan}

Sichuan province is well-known for its tourism resources, including 4 world heritages, 17 national 4A-level scenic spots, and 4 natural reserves listed in the Man and Biosphere and its World Network of Biosphere Reserves by UN, 17 national nature reserves, 15 national scenic area, 25 national forest parks, one world geological park, 8 national geological parks, 62 national key cultural relics protection units, 10 excellent tourism cities in China and 7 famous historical and cultural cities, etc. In recent years, as the tourism of Sichuan has been continuously expanded in the scale and relevant elements have supported it gradually, the tourism industry has begun to take shape. Different industries have got coordinate development and the system has been improved.

\section{MARKET ANALYSIS}

\section{A. Market Background}

The first tourist supermarket opened in China in 2001, and the new term "tourist supermarket" has attracted people's attention at a rapid pace. With the development of the times, tourist supermarkets have established in domestic well-known large tourist cities. 
Tourist supermarkets have been developing rapidly nationwide. As people's living standards have improved, as a consumer product, tourism has become an indispensable part in the leisure time of the public. At present, the proportion of self-guided tour is increasing in various cities, but the way of tour guide in tour agencies is still the mainstream of Chinese tourism.

As the tertiary industry, tourism consumption has stimulated domestic consumption market and made a great contribution. Generally, the tourist supermarkets in different scenic spots utilize the business pattern that the tour guide plans and organizes tours first and get push money later according to regulations. Therefore, it urgently needs software with comprehensive functions, which not only has the same purchase-sell-stock management system as ordinary supermarket, but also business management on tourism.

\section{B. Consumer Analysis}

Tourism consumption is a behavior under the influence of consumption psychology and changes with consumption psychology. Though it's in common with other consumption behaviors, tourism consumption has its own characteristics and laws. According to the analysis of consumption behaviors from the perspective of consumption psychology, it shows that tourism consumption has the characteristics of being habitual and imitative, irreversibility and complexity and so on.

\section{Competitor Analysis}

Our competitors are Ctrip and Tuniu and so on, which are also tourist supermarkets. Compared with Ctrip, Lebu Sishu tourist supermarket has distinguishing advantages: it has relatively low prices and relatively standardized service, and is quite familiar with Sichuan. It aims at offering customer service to customers who travel to Sichuan and Chongqing. These customers can enjoy considerate service at a price slightly lower than Ctrip. For example, through Lebu Sishu and local travel service, customers can pay relatively low prices but enjoy relatively thoughtful service. So, consumers can consider about the time cost and price sensitive to choose freely.

There are reasons why Lebu Sishu can offer tourism service at a relatively low price. As a product only for local travel service, Lebu Sishu covers a smaller range of services than large supermarkets like Ctrip and Tuniu, so its service is considerate. We only cooperate with travel agencies in Sichuan province, which play a big role in local business. Moreover, Lebu Sishu introduces a new service - panoramic virtual visit, which other tourist supermarkets don't possess. With Lebu Sishu, users can enjoy the scenery of Sichuan without traveling to the destination or choose to go sightseeing personally. Furthermore, Lebu Sishu has also provided ticket booking for scenic spots including scenic spots in Sichuan.

\section{BRAND DESIGN}

\section{A. Design Concept}

In modern times, new media is under rapid development and people's living standard is improving. The subject in this paper is about - a tourist supermarket targeting at Sichuan region - Lebu Sishu tourist supermarket emerges as the times require. Lebu Sishu is derived from the idiom "One has much enjoyment and forgets to go back home", and it has something in common with the meaning of the idiom while it's a little different. Its meaning is that when the audience uses this product, they can enjoy themselves during tours in Sichuan region; Shu stands for abbreviation of the Sichuan province, which makes it clear to the audience that the product is focused on tourism in Sichuan region. Therefore, it's named Lebu Sishu.

\section{B. Logo Design}

A logo represents a product and embodies the image of the product. Lebu Sishu tourist supermarket is designed with the image of a "chili pepper fish". Chili pepper has become a representative symbol of Sichuan region. It lacks of attractive elements if it is used as a symbol of new media app alone. So the $\log 0$ is designed to be a combination of chili pepper and fish - coming from "Fish can swim in the sea as they will" as shown in "Fig. 1".

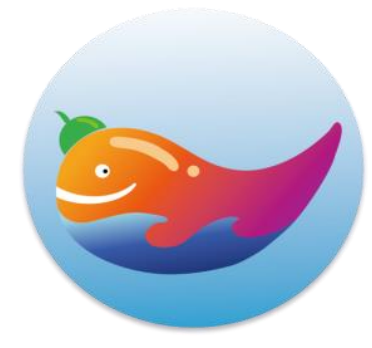

Fig. 1. Logo design.

\section{Standard Color Design}

The standard color is designed with blue, rose red, orange and green. Part of the main fish pattern uses warm color, emphasizing on characteristics of the image "chilli pepper fish". The rest part uses blue which means freedom. Combining these colors forms the essence of the logo.

\section{APPLICATION SYSTEM DESIGN}

\section{A. Dynamic Composition of the Symbol}

With the coming of information age, the use of logo not only refers to use in different occasions, technology helps the logo to give a full play to its function. As a method of advertising, dynamic logo reflects brighter and dynamic characteristics. It will be better to identify and convey information. So I designed a dynamic logo that can be used on mobile platforms, advertising platforms, and online platforms.

The design of the logo comes from the allusion of fish swimming in the sea as they wish, and combines with the 
representative of Sichuan, the chili pepper. At last, it formed a dynamic effect of a chili fish playing in the sea. (As video cannot play on paper, we can scan the $\mathrm{QR}$ code to watch as shown in "Fig. 2".

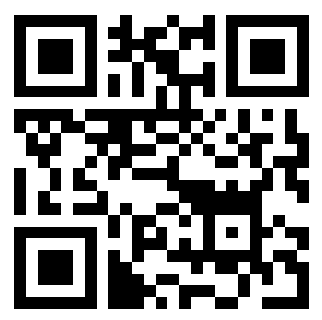

Fig. 2. Dynamic symbol.

\section{B. Publicity Video}

Through the video, it can convey the concept, culture, image and function of Lebu Sishu tourist supermarket. At the same time, it introduces landmark tourist attractions, food and culture of Sichuan region. With slogan "Have fun with us", there are a series of adventures and carnivals, and the interactive point that is set on the screen makes audience generate interests and would like to interact with the video.

Through screen, sound and interaction, the video comprehensively shows the image of Lebu Sishu tourist supermarket, and attract the audience. It plays the role of advertising. The video includes three parts. When it's produced, the technique of stop-motion is used. At the beginning, it introduces how to watch the video and the middle part outlines the scenic spots in Sichuan region. At last, it shows the function and image of Lebu Sishu tourist supermarket as shown in "Fig. 3".

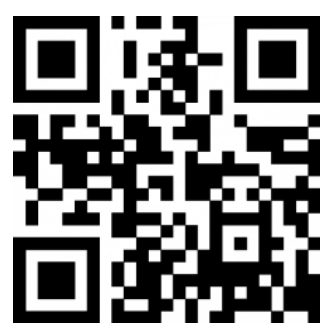

Fig. 3. Publicity video.

\section{DESIGN OF TRADITIONAL PUBLICITY}

\section{A. Design of Flip Books}

Flip books make people recall childhood when we had fun, attracting the attention of the audience. Meanwhile, slogan and logo design is added on the books, which form dynamic effect when reading; it will leave a distinct impression on the audience. The size of the flip book is $14.5^{*} 9 \mathrm{~cm}$ so it's easy to take and store.

\section{B. Postcard Design}

As an indispensable present during the travel, postcard has integrated function and publicity, so the front is a picture of walking in Sichuan region while the back is with concisestyle design, which is easy to collect and carry as shown in "Fig. 4".

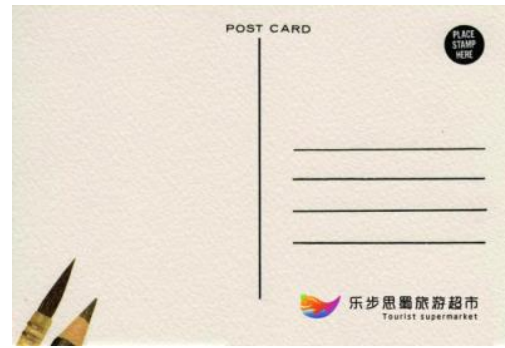

Fig. 4. Postcard design

\section{Pillow Design}

With a pillow, people will feel a sense of security and use it to have a rest. When they are tired during tours, pillows can be a gift or for sales as shown in "Fig. 5".

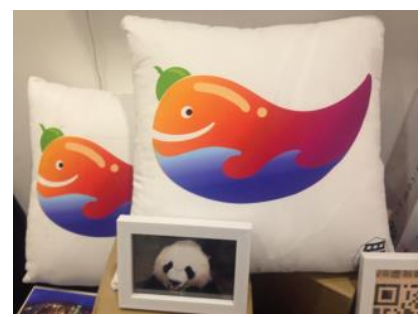

Fig. 5. Pillow design

\section{Design of Handbag and Gift Bag}

At present, to protect the environment and green development has become the concept of economic development in our country and even the world. Whether the environment is in a good condition or not is very essential to us. In this way, I designed a handbag, which can be repeatedly used. It has played an important role in environmental protection. In addition to using the handbag, it makes an advertisement for Lebu Sishu as shown in "Fig. 6".

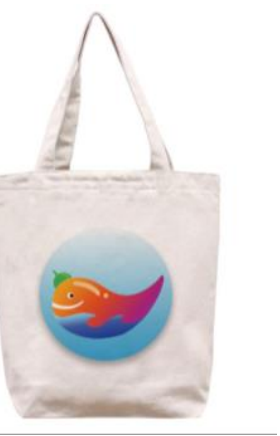

Fig. 6. Design of handbag.

In addition, the gift bag is also designed, which adopts the style of modernism, combining geometry and logo design as shown in "Fig. 7". 


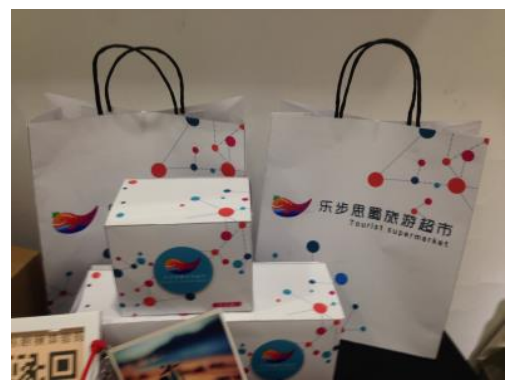

Fig. 7. Design of gift bag.

\section{E. Gift Box}

Gift box also uses the modernistic style, combining geometry and logo design. A QR code is added to the gift box, so that customers can follow the public number of Lebu Sishu on WeChat to know about news and attend activities after scanning the QR code as shown in "Fig. 8".

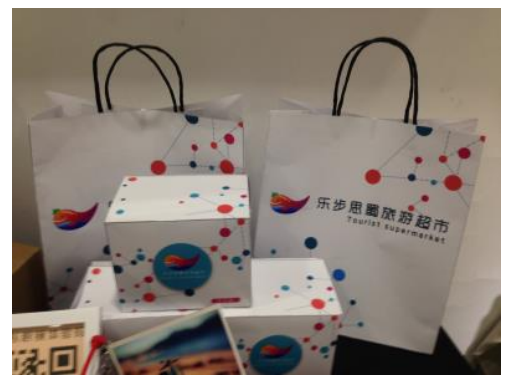

Fig. 8. Design of gift box.

\section{F. Poster}

The theme of the poster I designed mainly reflects the image and function of Lebu Sishu. As a student majored in advertising, we need to design advertisements with various and multi-level theme elements. The poster is concise and clear with the background of lattices, which can foil the picture. The main representatives are chili pepper fish, sea and functional element, which embody the integration of modern and scientific technology in the Lebu Sishu tourist supermarket as shown in "Fig. 9".

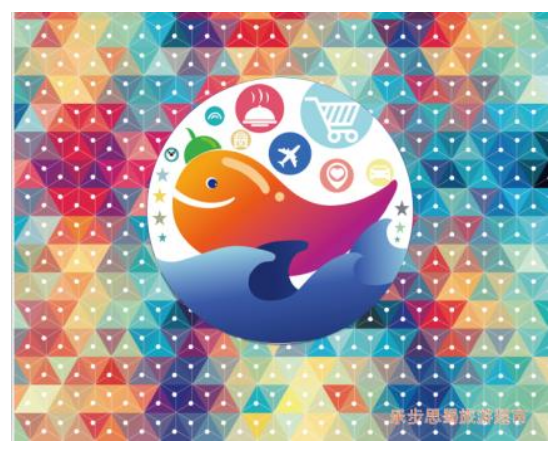

Fig. 9. Poster design.

\section{CONCLUSION}

Now, new media has changed the way people use the media and makes people's life more convenient. The development of technology determines in what direction the media industry is developing. Based on what achievements new media achieves in new media era, it will become a mainstream in the future media industry. In the new era, the tourism industry as a tertiary industry has developed rapidly with the new media. The new media mainly including smartphones and the Internet offers a wider platform for promotion and marketing of tourism products.

\section{REFERENCES}

[1] Wang Lepeng, Yao Mingguang \& Wang Yijun. A research overview of marketing of tourism enterprises on new media[J]. China Market, 2011(36): 83-84.

[2] Ju Yi, Huaxi. The first love's river of China - a review on the concept and planning of image positioning of sightseeing place. Journal of Suzhou Institute of Urban Construction and Environmental Protection, 2001 (3).

[3] Liu Hengtao. Yoozai.com - Online travel supermarket. Manager, the 207th period. 